\title{
Complications due to Inadvertent Release of Cannula During Phacoemulsification
}

\author{
Arvind Gupta, Renuka Srinivasan, K Ramesh Babu \\ Department of Ophthalmology, Jawaharlal Institute of Postgraduate Medical Education and \\ Research, Pondicherry, India
}

\begin{abstract}
Aim: To report the occurrence of intraoperative complications caused by accidental release of either a viscoelastic or hydrodissection cannula.

Methods: This was a retrospective study from 1 January 2004 to 30 December 2009. The records of patients undergoing phacoemulsification during this period were reviewed. The records of patients with complications due to inadvertent release of either a viscoelastic agent cannula or a hydrodissection cannula were reviewed and the data were collected.

Results: Four patients had complications due to inadvertent cannula release during this period. The complications noted were zonular dialysis with vitreous prolapse, hyphaema, posterior capsular rupture with vitreous loss, and nucleus drop with vitreous loss. The final best-corrected visual acuity in 3 patients was 20/30, and 20/40 in the fourth patient due to chronic cystoid oedema.

Conclusion: Complications due to accidental release of the cannula are unfortunate and can be easily avoided by adopting few simple precautions.
\end{abstract}

Key words: Cannula, Intraoperative complications, Phacoemulsification, Viscoelastic substances

Asian J Ophthalmol. 2011;13:9-11.

\section{Introduction}

latrogenic intraoperative complications due to inadvertent intraocular release of either viscoelastic or hydrodissection cannulae have been sparsely reported..$^{1-6}$ This is surprising because cannulae are used during most anterior segment procedures, and most surgeons have probably encountered inadvertent release of cannulas during cataract surgery. The rarity of the reporting may be due to the legal implications of such a complication. $^{2}$

This study aims to report intraocular complications following inadvertent release of either hydrodissection or viscoelastic cannulas in patients undergoing phacoemulsification from 1 January 2004 to 30 December 2009. The purpose of the study was to investigate the spectrum of injuries caused by the release of a cannula and the incidence. Measures to prevent this event from occurring are also discussed.

Correspondence: Dr Arvind Gupta, Department of Ophthalmology, Jawaharlal Institute of Postgraduate Medical Education and Research, Pondicherry 605 006, India.

Tel: (91 413) 227 2763;

E-mail: arvind_ophthal@yahoo.co.in

\section{Methods}

The medical records of all patients undergoing phacoemulsification were retrospectively reviewed. Patients in whom either a hydrodissection cannula or a viscoelastic cannula was accidentally released in the eye while injecting balanced salt solution (BSS) or viscoelastic agent intraocularly during anterior segment surgery were included. The preoperative status, type of surgery, mechanism and site of injury, late impact, and visual outcomes of these patients were recorded. The follow-up period was 2 to 6 months. Institutional review board approval of the study was obtained.

\section{Results}

5210 patients underwent phacoemulsification during the 6-year period, of whom 4 had inadvertent release of cannula intraoperatively, and experienced complications due to the release. Thus, the incidence of such complications was $0.08 \%$. There were 3 men and 1 woman (age range, 58-68 years). Inadvertent release of a viscoelastic cannula occurred in 3 patients and inadvertent release of a hydrodissection cannula occurred in 1 patient.

In patient 1, the cannula was released and the tip of the cannula hit the ciliary sulcus in the opposite quadrant at 
6 'o clock. This led to zonular dialysis, and vitreous prolapse occurred. Phacoemulsification was converted to extracapsular cataract extraction (ECCE) and anterior vitrectomy was performed. The intraocular lens (IOL) was placed in the bag along with the capsular tension ring.

In patient 2, the tip of the cannula hit the iris in the inferior quadrant, leading to severe intraoperative persistent hyphaema. Intraoperative visibility was compromised and the IOL was inadvertently placed in the sulcus. Postoperatively, IOL decentration was noted resulting in a best-corrected visual acuity (BCVA) of 20/30.

In patient 3 the hydrodissection cannula released during hydrodissection. This led to rupture of the posterior capsule, near to the equatorial region. Phacoemulsification had to be aborted and was converted to ECCE.

Patient 4 had nucleus drop. After hydrodissection, while injecting viscoelastic to ascertain free rotation of the nucleus, the cannula became dislodged and hit the centre of the nucleus. The force of the viscoelastic agent and the cannula was transmitted to the posterior capsule via the nucleus, which ruptured and the nucleus dropped into the vitreous. The patient underwent pars plana vitrectomy and the nucleus was removed. The IOL was placed in the sulcus. Postoperatively, the patient developed chronic macular oedema, which compromised the final BCVA of 20/40.

The details of the 4 patients are shown in Table 1.

\section{Discussion}

Complications due to inadvertent release of a cannula from the syringe have been reported for both hydrodissection and viscoelastic cannulas. A hydrodissection cannula can be accidentally released during hydrodissection ${ }^{1,2}$ or corneal wound hydration. ${ }^{2-4}$ The reported complications due to accidental release of a cannula are severe hyphaema, ${ }^{2,6}$ posterior capsular rupture,,$^{2,3,5}$ vitreous haemorrhage, ${ }^{3}$ retinal breaks and retinal detachment, ${ }^{5}$ subhyaloid haemorrhage, ${ }^{6}$ and macular scarring ${ }^{2}$ (Table 2). However, to the authors' knowledge, nucleus drop has not been reported as a complication.

The accidental release of a cannula during anterior segment surgery may be attributed to 4 main factors. ${ }^{2}$ The first factor is insecure attachment of the cannula to the syringe. The second

Table 1. Details of 4 patients who had inadvertent intraoperative release of a cannula.

\begin{tabular}{|c|c|c|c|c|c|c|c|}
\hline $\begin{array}{l}\text { Patient } \\
\text { number }\end{array}$ & $\begin{array}{c}\text { Age } \\
\text { (years)/sex }\end{array}$ & $\begin{array}{l}\text { Type of } \\
\text { cannula } \\
\text { causing } \\
\text { injury }\end{array}$ & $\begin{array}{l}\text { Step during which } \\
\text { injury occurred }\end{array}$ & $\begin{array}{l}\text { Area of } \\
\text { impact }\end{array}$ & $\begin{array}{l}\text { Extent of } \\
\text { damage }\end{array}$ & $\begin{array}{c}\text { Extra } \\
\text { management }\end{array}$ & $\begin{array}{l}\text { Final } \\
\text { BCVA }\end{array}$ \\
\hline 1 & $65 /$ male & VC & $\begin{array}{c}\text { Before } \\
\text { capsulorrhexis }\end{array}$ & Ciliary sulcus & $\begin{array}{c}\text { Zonular dialysis from } \\
4-8 \text { o'clock }\end{array}$ & $\begin{array}{l}\text { Phacoemulsification converted to } \\
\text { ECCE, anterior vitrectomy, } \\
\text { and implantation of capsular } \\
\text { tension ring }\end{array}$ & $20 / 30$ \\
\hline 2 & $68 /$ male & VC & Before implanting IOL & $\begin{array}{c}\text { Angle of the anterior } \\
\text { chamber }\end{array}$ & $\begin{array}{l}\text { Anterior chamber } \\
\text { hyphaema }\end{array}$ & $\begin{array}{l}\text { Washed the anterior chamber to } \\
\text { clear hyphaema and blood clots }\end{array}$ & $20 / 30$ \\
\hline 3 & $64 /$ male & $\mathrm{HC}$ & During hydrodissection & Posterior capsule & $\begin{array}{l}\text { Posterior capsular } \\
\text { rupture with vitreous } \\
\text { loss }\end{array}$ & $\begin{array}{l}\text { Anterior vitrectomy and IOL } \\
\text { implanted in the ciliary sulcus }\end{array}$ & $20 / 30$ \\
\hline 4 & 58/female & VC & After hydrodissection & $\begin{array}{l}\text { Centre of the } \\
\text { nucleus }\end{array}$ & $\begin{array}{l}\text { Nucleus drop with } \\
\text { vitreous loss }\end{array}$ & $\begin{array}{l}\text { Pars plana vitrectomy with nucleus } \\
\text { retrieval and } \mathrm{IOL} \text { implanted in the } \\
\text { ciliary sulcus }\end{array}$ & $20 / 40$ \\
\hline
\end{tabular}

ECCE = extracapsular cataract extraction; $\mathrm{HC}=$ hydrodissection cannula; $\mathrm{IOL}=$ intraocular lens; $\mathrm{VC}=$ viscoelastic cannula.

Table 2. Previously reported cases of inadvertent intraoperative release of a cannula.

\begin{tabular}{|c|c|c|c|c|}
\hline Authors & Type of cannula & Ocular injuries & Type of surgery & Final BCVA \\
\hline Buys et al, $2009^{6}$ & VC & $\begin{array}{l}\text { Intraoperative severe hyphaema, } \\
\text { subhyaloid haemorrhage }\end{array}$ & Phacotrabeculectomy & $20 / 70$ \\
\hline \multirow[t]{2}{*}{ Rumelt et al, $2007^{2}$} & $\mathrm{HC}$ & $\begin{array}{l}\text { Corneal contusion or corneal oedema, } \\
\text { iris or angle contusion, capsular tear } \\
\text { and vitreous loss }\end{array}$ & $\begin{array}{c}\text { Cataract surgery } \\
\text { (5 ECCE and } 1 \text { phacoemulsification) }\end{array}$ & $\begin{aligned} 20 / 40(n=3) \\
20 / 30(n=1) \\
20 / 20(n=1) \\
20 / 100(n=1)^{\star}\end{aligned}$ \\
\hline & VC & Vitreous loss and macular contusion & Penetrating keratoplasty & $<3 / 120$ \\
\hline Bradshaw et al, $2006^{4}$ & $\mathrm{HC}$ & Iris hole, hyphaema and vitreous haemorrhage & Phacoemulsification & $6 / 9$ \\
\hline Munshi et al, $2005^{1}$ & $\mathrm{HC}$ & Zonular dialysis and vitreous loss & Phacoemulsification & Not reported \\
\hline Prenner et al, $2003^{5}$ & VC & $\begin{array}{l}\text { Posterior capsular tear, vitreous loss } \\
\text { and retinal breaks }\end{array}$ & Phacoemulsification & $20 / 20$ \\
\hline
\end{tabular}

*One patient developed anterior ischaemic optic neuropathy.

$\mathrm{BCVA}=$ best-corrected visual acuity; $\mathrm{ECCE}=$ extracapsular cataract extraction; $\mathrm{HC}=$ hydrodissection cannula; $\mathrm{VC}=$ viscoelastic cannula 
factor is the forceful injection of the agent into the eye. The third factor involves the physical properties of the syringe and intraocular agent injected, in terms of the viscosity of the injected agent, the ratio of the diameter and length of the cannula, and the patency of the cannula. The resistance to flow is directly proportional to the viscosity of the agent injected and length of the cannula and inversely proportional to the diameter of the cannula (Bernoulli's law). The fourth factor relates to a non-patent or partially patent cannula, which increases the force required to inject the viscoelastic or BSS inside the eye and the tendency for sudden detachment of the cannula. ${ }^{3}$

These complications can be avoided by following precautions such as using syringes with locks (eg, Luer Lock syringe) while injecting BSS or viscoelastic into the eye. The surgeon should attempt to inject the solution outside the eye to ensure the security of the cannula and its patency. If the surgeon encounters any undue resistance while injecting the solution, then the patency of the cannula should be questioned and it should be replaced. Intraocular injection should be slow and gentle. The assisting staff should tighten the cannula onto the syringe, which should be crosschecked by the operating surgeon. Holding the cannula during intraocular injection will further reduce the risk of inadvertent release of the cannula. The cannula's tip should point towards the periphery or angle of the anterior chamber and not the posterior pole when filling up the anterior chamber, while the tip should point towards the ciliary processes when filling up the posterior chamber. This helps to avert any sight-threatening complications if accidental release of the cannula does occur.

In conclusion, accidental release of a cannula during anterior segment surgery is a rare avoidable iatrogenic intraoperative complication that may cause serious sight-threatening intraocular injuries and hence adequate preventive measures should be taken.

\section{References}

1. Munshi V, Sampat V, Pagliarini S. Zonular dialysis and vitreous loss with a J-shaped hydrodissection cannula during phacoemulsification. J Cataract Refract Surg. 2005;31:450-1.

2. Rumelt $S$, Kassif $Y$, Koropov $M$, et al. The spectrum of iatrogenic intraocular injuries caused by inadvertent cannula release during anterior segment surgery. Arch Ophthalmol. 2007;125:889-92.

3. Dinakaran S, Kayarkar W. Traumatic retinal break from a viscoelastic cannula during cataract surgery. Arch Ophthalmol. 2004;122:936.

4. Bradshaw SE, Shankar P, Maini R, Ragheb S. Ocular trauma caused by a loose slip-lock cannula during corneal hydration. Eye. 2006;20:1432-4.

5. Prenner JL, Tolentino MJ, Maguire AM. Traumatic retinal break from viscoelastic cannula during cataract surgery. Arch Ophthalmol. 2003;121:128-9.

6. Buys YM, Firat M, Brent MH. Posterior capsular rupture secondary to viscoelastic cannula and luer-lock release during phacotrabeculectomy. Can J Ophthalmol. 2009;44:102-3. 